\title{
WMS - Warehouse Management System: adaptação proposta para o gerenciamento da logística reversa
}

\author{
Patrícia Guarnieri \\ CEFET - PR \\ Daniele Chrusciack \\ UNIPAN - PR \\ IVANIR LUIZ DE OLIVEIRA \\ CEFET - PR \\ Kazuo Hatakeyama \\ CEFET - PR \\ LuCiano ScandelarI \\ CEFET - PR
}

\begin{abstract}
Resumo
Com o advento da globalização, e o conseqüente atendimento a mercados distantes e alta rotatividade dos estoques, os armazéns descartam quantidades enormes de materiais ao final do processo logístico. Estes materiais, além de representarem considerável valor econômico, podem causar danos ao meio ambiente se descartados de forma indiscriminada. Umas das formas de evitar estes problemas, é através da adoção de técnicas de Gerenciamento da Cadeia de Suprimentos Reversa. Para que estas técnicas sejam colocadas em prática em larga escala, são necessários Sistemas para o Gerenciamento da Cadeia de Suprimentos Reversa. Como estes sistemas praticamente inexistem no mercado, este artigo propõe uma adaptação do WMS tradicional, de forma a ser possível utilizá-lo também para o gerenciamento da cadeia de suprimentos reversa. A metodologia proposta evidencia que a maioria das funções do WMS tradicionalmente utilizadas para gerenciar a logística direta também pode ser utilizada na logística reversa.
\end{abstract}

Palavras-chave

Cadeia de suprimentos, Logística, Logística reversa, Tecnologia da informação.

\section{WMS - Warehouse Management System: adaptation propused for the management of the reverse logistics}

\begin{abstract}
With the advent of the globalization, warehouses serves distant markets and presents a very low stock turnaround time. In this process, huge quantities of materials are discarded at the end of the logistics chain. These materials represent a considerable financial ammount and, if improperly discarded, can cause an environmental disaster. In order to avoid these problems, reverse supply chain management techniques are used. On order to implement these techniques, reverse supply chain management systems are needed. As this kind of systems are almost inexistent, this article suggests the adaptation of the traditional WMS systems in order to be useful in the management of the reverse supply chain management. The proposed methodology shows that the major functions found in present WMS systems can also be used for reverse supply chain management.
\end{abstract}

\section{Key words}

Information Technology, Logistics, Reverse Logistics, Supply Chain. 


\section{INTRODUÇ̃̃O}

O ambiente empresarial está submetido a constantes mudanças, principalmente após a crescente globalização dos mercados. As empresas viram aumentar a sua responsabilidade perante o mercado consumidor e com a plena satisfação dos clientes, além de se depararem com a concorrência mundial. Para manter-se no mercado, muitas empresas mudaram completamente seus processos produtivos e de atendimento ao consumidor.

Para se enquadrarem no mesmo patamar de seus concorrentes, as empresas resgataram um antigo conceito de administração dos fluxos de bens, serviços e informações, utilizado principalmente no contexto militar, a logística empresarial.

Segundo Ballou (2001:21), "a missão da logística é dispor a mercadoria ou o serviço certo, no lugar certo, no tempo certo e nas condições desejadas, ao mesmo tempo em que fornece a maior contribuição à empresa".

Ainda pode-se acrescentar que a empresa deve, além de realizar todas as atividades de acordo com a missão da logística, satisfazer o seu cliente, pois é ele quem proporciona a sustentação da empresa em um mercado competitivo. O desenvolvimento da logística empresarial tem sido exponencial nos últimos anos, por ser fator essencial para a competitividade das empresas. Existem diversos fatores que aceleraram este desenvolvimento: a pressão por maior giro e redução de estoques, o atendimento a mercados distantes, a introdução de novas tecnologias, o curto ciclo de vida dos produtos, entre outros.

Ao final de todos os processos logísticos realizados nos armazéns, são descartadas quantidades enormes de materiais como fitas de arquear aço e plástico, papelão, caixas plásticas, paletes de madeira, filmes de polietileno, espumas plásticas, entre outros. Estes materiais além de não poderem mais ser simplesmente atirados em um aterro sanitário, causando sérios impactos ao meio ambiente, constituem bens que podem ser reutilizados nos processos produtivos, proporcionando retorno econômico às empresas.

Existem também os produtos que por diversos motivos retornam ao armazém sem uso, devolvidos por problemas de validade, garantia, qualidade, avarias no transporte e devem também ser encaminhados para retroprocessadores para terem alguns ou todos seus componentes reaproveitados, também gerando retorno econômico.

Para dar suporte a todas essas mudanças ocorridas no ambiente empresarial e possibilitar que as atividades do sistema logístico direto sejam administradas corretamente tornou-se necessária a utilização de sistemas de infor- mação logísticos ou de gerencimento da cadeia de suprimentos, viabilizados tecnicamente através da tecnologia da informação.

Atualmente, inexistem no mercado sistemas de informação específicos para o gerenciamento da logística reversa. Por isso o presente artigo propõe a adaptação de um sistema de gerenciamento da cadeia de suprimentos já existente, o WMS - Sistema de Gerenciamento de Armazéns, para atender tal necessidade.

\section{LOGÍSTICA EMPRESARIAL VERSUS GERENCIAMENTO DA CADEIA DE SUPRIMENTOS}

A logística empresarial, de acordo com Pozo (2002), trata de todas as atividades de movimentação e armazenagem que viabilizam a movimentação de produtos desde a compra da matéria-prima até o consumidor final, bem como dos fluxos de informação que dão suporte à movimentação dos produtos e serviços com o objetivo de providenciar níveis de serviço adequados aos clientes a um custo acessível. Segundo Ribeiro \& Gomes (2004), logística é o processo de gerenciar estrategicamente a aquisição, movimentação e armazenamento de materiais, peças e produtos acabados, sua organização e dos seus canais de distribuição de modo a poder maximizar a lucratividade da empresa e o atendimento e satisfação dos clientes a baixo custo.

\section{^ s necessidades da logística reversa também provêm das legislações que proíbem o descarte indiscriminado de resíduos no meio ambiente.}

A logística é um dos principais fatores que proporcionaram o diferencial competitivo que as empresas necessitavam para manter-se em um mercado globalizado, de forma a satisfazer o cliente, visando a maximização do lucro. Apesar de ter sua origem há muitos anos atrás, na área militar, e ter seus primeiros registros por volta do ano de 1800 , nos escritos do engenheiro francês Julie Dupuit, ela somente teve verdadeira ênfase no Brasil por volta de 1990, após a abertura de mercados. Para melhor compreender a relação entre logística e cadeia de suprimentos, Ballou (2001, p. 22) afirma que:

Uma empresa geralmente não está habilitada a controlar seu fluxo de produto inteiro no canal, desde as fontes de matéria-prima até o ponto final de 
consumo, embora esta seja uma oportunidade emergente. Normalmente, o máximo controle gerencial que pode ser esperado está sobre o suprimento físico imediato e sobre os canais de distribuição física. O canal de suprimento físico refere-se ao hiato de tempo e espaço entre as fontes de material imediato de uma empresa e seus pontos de processamento. Da mesma maneira, o canal de distribuição física refere-se ao hiato de tempo e espaço entre clientes. Devido às similaridades nas atividades entre os dois canais, o suprimento físico e a distribuição física compreendem as atividades que estão integradas na logística empresarial. O gerenciamento da logística empresarial é também popularmente chamado de gerenciamento da cadeia de suprimentos.

O conceito de gerenciamento da cadeia de suprimentos ou gerenciamento logístico integrado, de acordo com Christopher (1997), é entendido como a gestão e a coordenação dos fluxos de informações e materiais entre a fonte e os usuários como um sistema, de forma integrada. A ligação entre cada fase do processo, na medida em que os produtos e materiais se deslocam em direção ao consumidor é baseada na otimização, ou seja, na maximização do serviço ao cliente, enquanto se reduzem os custos e os ativos detidos no fluxo logístico. os pontos de processamento da empresa e seus

fornecedores. Vale ainda ressaltar que tudo isso deve ser permeado por sistemas de informações que dêem suporte ao processo, para que, dessa forma, a organização consiga agregar ao produto acabado valor perceptível aos consumidores finais.

Uma visão mais abrangente do processo do gerenciamento da cadeia de suprimentos, que não termina com a simples entrega do produto ao consumidor final, mas também se preocupa com o fluxo reverso desses bens, constitui-se em uma preocupação crescente das empresas, pois considerando-se que as organizações hoje atuam em um mercado global, as exigências de fornecedores e clientes quanto a questões ambientais se multiplicam, tornando-se um fator de peso em negociações.

\section{LOGÍSTICA REVERSA OU GERENCIAMENTO REVERSO DA CADEIA DE SUPRIMENTOS}

Existe um aumento constante do nível de descartabilidade dos produtos em geral. Isto ocorre devido à redução do ciclo de vida dos produtos e maior giro dos estoques. $\mathrm{O}$ avanço da tecnologia também é um fator relevante que acelera a obsolescência dos produtos. Segundo Leite, (2003), com o aumento do descarte dos produtos de utilidade após seu primeiro uso, há um desequilíbrio entre as quantidades de resíduos descartadas e as reaproveitadas, tornando o lixo urbano um dos mais graves problemas ambientais da atualidade. Isto se dá porque muitas vezes não encontram canais de distribuição reversos pós-consumo e pós-venda devidamente estruturados e organizados nas empresas.

Esses resíduos, gerados na maioria das vezes pelas indústrias e pelos armazéns,

Para corroborar este conceito Chopra \& Meindl (2003), afirmam que o objetivo de toda cadeia de suprimento é maximizar o valor global gerado. O valor gerado por uma cadeia de suprimentos é a diferença entre o valor do produto final para o cliente e o esforço realizado pela cadeia de suprimento para atender ao seu pedido.

$\mathrm{Na}$ verdade, existe ainda muita confusão nos termos logística e gerenciamento da cadeia de suprimentos. O gerenciamento da cadeia de suprimentos, segundo Wanke (2003), é uma tarefa mais complexa que a gerência logística dos fluxos de produtos, serviços e informações relacionadas do ponto de origem para o ponto de consumo, ou seja, a estratégia logística é necessária no gerenciamento da cadeia de suprimentos, porém este visa além da gerência logística, uma maior integração das atividades das organizações, além do estabelecimento de relacionamentos confiáveis e duradouros com clientes e constituem materiais que podem ser reaproveitados e reintegrados ao processo produtivo. Para que isso ocorra de forma eficiente, são necessários sistemas que gerenciem esse fluxo reverso, de maneira similar ao que acontece no fluxo direto. Muitas vezes o processo logístico reverso requer as mesmas atividades utilizadas no processo logístico direto.

De acordo com Bowersox \& Closs (2001), as necessidades da logística reversa também provêm das legislações que proíbem o descarte indiscriminado de resíduos no meio ambiente e incentivam a reciclagem de recipientes de bebidas e materiais de embalagem. $\mathrm{O}$ aspecto mais significativo da logística reversa é a necessidade de um máximo controle quando existe uma possível responsabilidade por danos à saúde humana, por exemplo produtos vencidos ou contaminados. Assim, a retirada dos mesmos do mercado é semelhante a uma estratégia de 
serviço máximo ao cliente que deve ser realizado sem se considerar o custo.

A logística reversa operacionaliza esta retirada dos produtos de mercado, tanto no que se refere a produtos vencidos ou contaminados, como também os produtos que estão no final de sua vida útil. Para melhor entendimento, tem-se o conceito de Leite (2003:16), que afirma:

\begin{abstract}
A logística reversa é a área da logística empresarial que planeja, opera e controla o fluxo e as informações logísticas correspondentes, do retorno dos bens de pós-venda e de pós-consumo ao ciclo dos negócios ou ao ciclo produtivo, por meio dos canais de distribuição reversos, agregando-lhes valor de diversas naturezas: econômico, ecológico, legal, logístico, de imagem corporativa, entre outros.
\end{abstract}

Ela pode ser ainda dividida em duas áreas de atuação: logística reversa de pós-venda e logística reversa de pósconsumo. A primeira pode ser entendida como a área da logística reversa que trata do planejamento, do controle e da destinação dos bens sem uso ou com pouco uso, que retornam à cadeia de distribuição por diversos motivos: devoluções por problemas de garantia, avarias no transporte, excesso de estoques, prazo de validade expirado, entre outros. A logística reversa de pós-consumo pode ser vista como a área da logística reversa que trata dos bens no final de sua vida útil, dos bens usados com possibilidade de reutilização (embalagens, paletes) e dos resíduos industriais.

Entende-se de melhor maneira o processo logístico reverso através da Figura 1, que segundo Rogers \& Tibben-Lembke (1999) é o processo de planejamento, implementação e controle do fluxo de matérias-primas, estoque em processamento e produtos acabados, como também de seu fluxo de informação, desde o ponto de consumo até o ponto de origem, com o objetivo de recuperar valor ou realizar um descarte final adequado.

A Figura 2, complementa a explicação do processo logístico reverso, demonstrando os canais reversos de revalorização dos resíduos de pós-consumo e pós-venda.

Como pode ser observado na Figura 1, a logística reversa se utiliza das mesmas atividades da logística direta. Para tanto, conforme demonstra a Figura 2, os

Figura 1: Gerenciamento da cadeia de suprimentos direta x reversa.

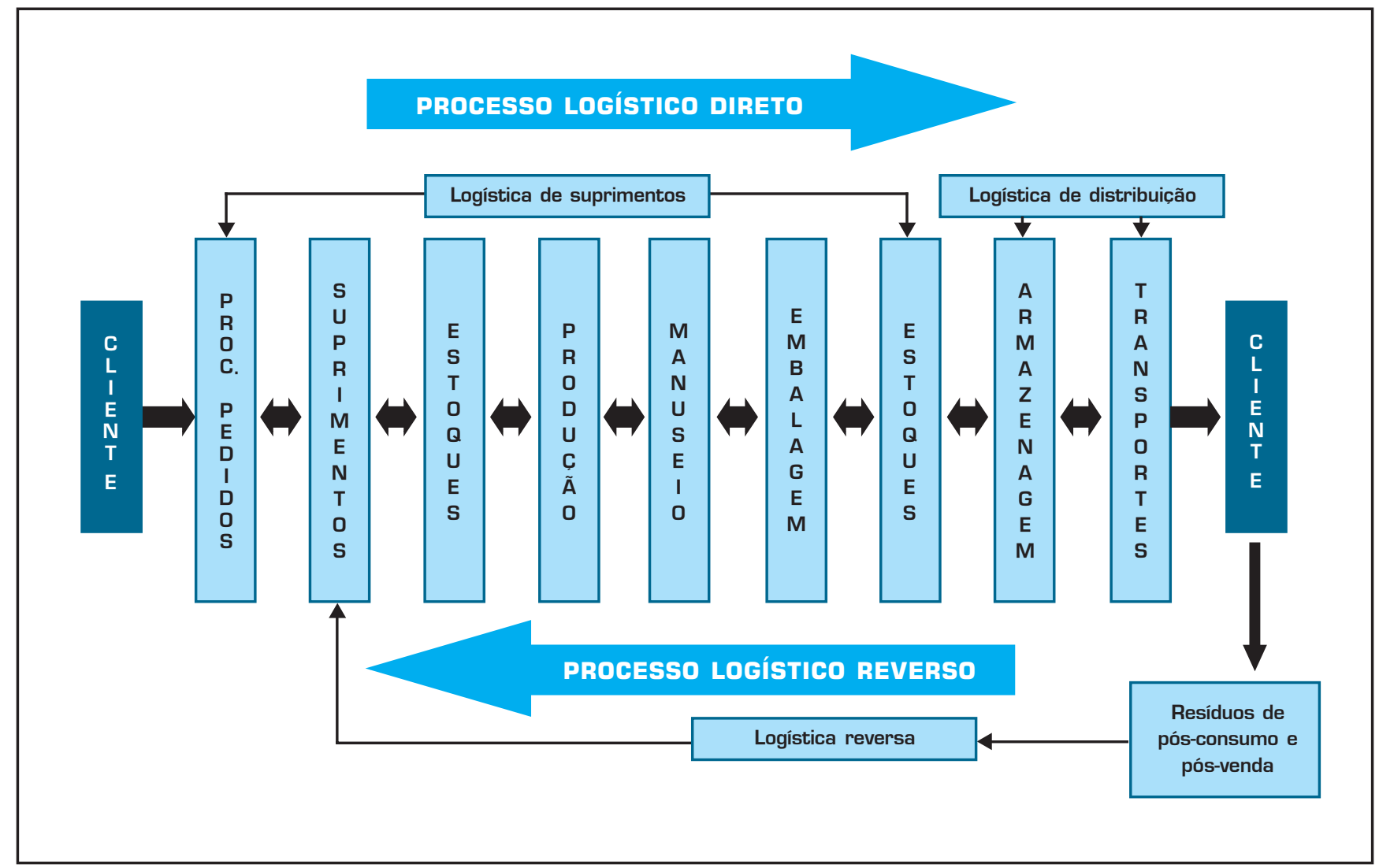

Fonte: Adaptado de Rogers \& Tibben-Lembke (1999, p.5). 
resíduos devem ser coletados embalados e expedidos, para posteriormente serem destinados aos canais reversos de revalorização, tais como: retorno ao fornecedor, revenda, recondicionamento, reciclagem e em último caso descarte, possibilitando seu retorno ao ciclo produtivo e/ou de negócios como materiais secundários.

É possível através das soluções que a logística reversa oferece no gerenciamento dos resíduos sólidos, fechar o ciclo da cadeia de suprimentos, desta forma gerando lucratividade, através da redução de custos e consolidação de uma imagem institucional positiva e ambientalmente responsável perante o mercado consumidor, além da oportunização de novos nichos de negócios que geram novos empregos e renda. (FELIZARDO, 2003)

\section{ATIVIDADE LOGÍSTICA DE ARMAZENAGEM}

As atividades logísticas absorvem uma parcela relevante dos custos totais das empresas, representando em média $25 \%$ das vendas e $20 \%$ do produto nacional bruto (POZO, 2002). Mas, para que se obtenha sucesso no processo logístico, é muito importante ter um sistema de informações que possa atender e dar suporte a todos os processos que compõem sua estrutura. A administração de materiais, o planejamento da produção, o suprimento e a distribuição física devem assim integrar-se para remodelar o gerenciamento dos recursos fundamentais.
A armazenagem é considerada uma das atividades de apoio ao processo logístico, que segundo Pozo (2002:23), "são as que dão suporte ao desempenho das atividades primárias, para que a empresa possa ter sucesso, que se obtém mantendo e conquistando clientes com pleno atendimento do mercado e satisfação total do acionista em receber seu lucro".

Ela abrange a administração dos espaços necessários para manter os materiais estocados na própria fábrica ou em armazéns terceirizados. Essa atividade é muito relevante, pois muitas vezes diminui a distância entre vendedor e comprador, além de envolver diversos processos como: localização, dimensionamento, recursos materiais e patrimoniais (arranjo físico, equipamentos, etc.), pessoal especializado, recuperação e controle de estoque, embalagens, manuseio de materiais, montagem/desmontagem, fracionamento e consolidação de cargas e conseqüentemente a necessidade de recursos financeiros e humanos.

De acordo com Arbache et al. (2004), uma instalação de armazenagem pode desempenhar vários papéis dentro da estrutura de distribuição adotada por uma empresa: recepção e consolidação de produtos de vários fornecedores, para posterior distribuição a diversas lojas de uma rede; recepção de produtos de uma fábrica e distribuição para diversos clientes. A armazenagem possui quatro atividades básicas: recebimento, estocagem, administração de pedidos e expedição.

Figura 2: Canais reversos de revalorização.

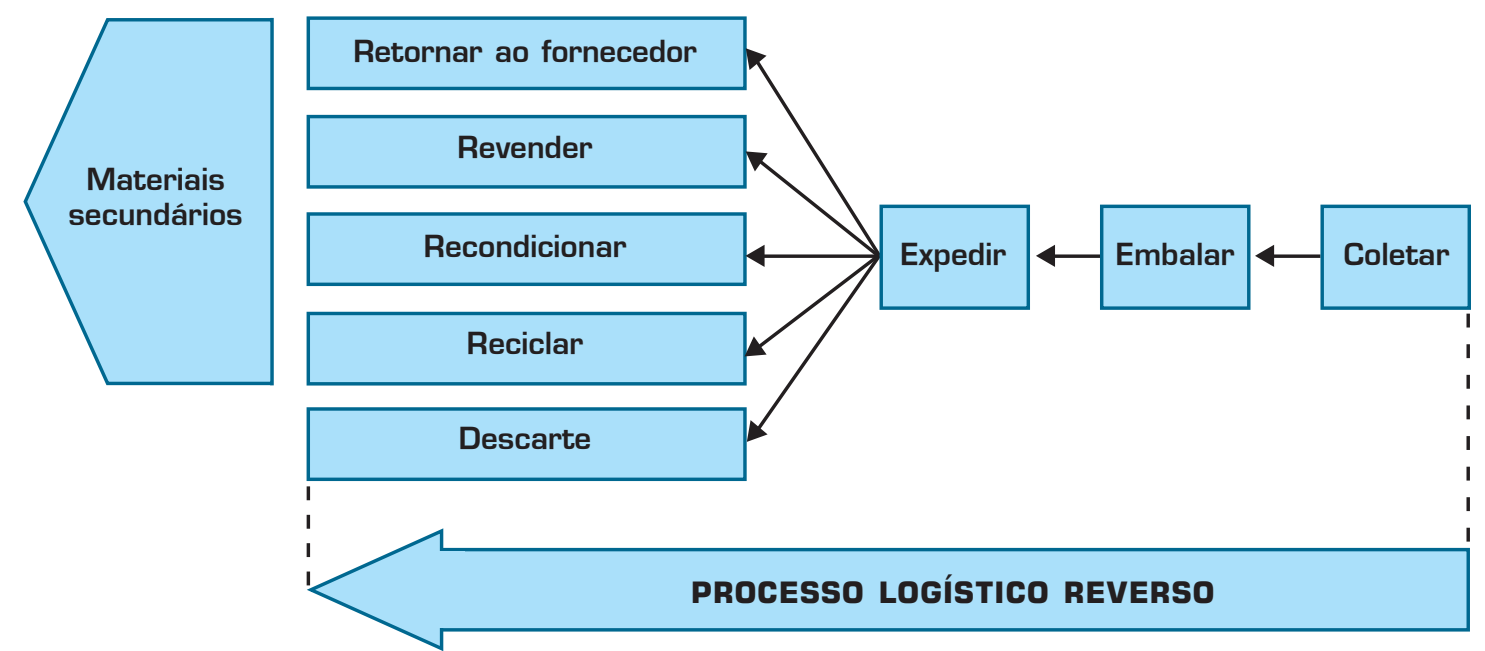

Fonte: Adaptado de Rogers \& Tibben-Lembke (1999). 


\section{SISTEMAS DE SUPPLY CHAIN MANAGEMENT (SCM) OU GERENCIAMENTO DA CADEIA DE SUPRIMENTOS [GCS)}

De acordo com Chopra \& Meindl (2003), os sistemas de tecnologia da informação (TI) são importantes em todo estágio da cadeia de suprimentos, pois permitem que as empresas reúnam e analisem as informações que são necessárias para a tomada de decisão. Eles podem ser segmentados de acordo com os estágios da cadeia de suprimentos e possuem níveis diferentes de funcionalidade que podem receber e apresentar informações diferenciadas e analisá-las para solucionar problemas a curto ou a longo prazo, podem ser utilizados para tomar decisões de estratégia, planejamento ou operação.

Para Arozo (2003), existe hoje uma nova onda de implantação de pacotes de tecnologia da informação: a dos Sistemas de Supply Chain Management (SCM) e segundo informações da consultoria Mckinsey, entre 1999 e 2002, foram vendidos mais de US\$ 15 bilhões em licenças para esses tipos de sistemas, não estando incluídos neste valor os gastos referentes aos processos de implantação e aos custos de manutenção. Apesar do grande investimento já realizado em âmbito mundial, no Brasil esse movimento está em fase inicial.

A figura 3 mostra o posicionamento e as funcionalidades dos sistemas de SCM. Segundo Arozo (2003) nota-se que, enquanto alguns módulos são focados em apenas um nível decisório e um processo (p. ex: TMS), outros abrangem mais de um nível de decisão (p. ex: Planejamento da Demanda) ou mais de um processo (p. ex: Planejamento mestre).

Os módulos operacionais trabalham com abrangência bastante restrita. À medida que as decisões vão tomando caráter mais estratégico, seus respectivos módulos ganham maior abrangência. Por exemplo, o módulo de Planejamento de rede cobre de forma simplificada todos os processos.

Segundo Banzato (1998), atualmente a armazenagem, uma das atividades dentro de uma cadeia de suprimentos, exige muito mais que simples procedimentos automatizados, ela necessita de sistemas de informação eficazes, que possam tomar decisões rápidas e inteligentes. A rentabilidade das empresas também é afetada diretamente pela eficiência de seu processo de armazenagem, logo as melhores práticas devem ser uma constante

Figura 3: Posicionamento dos sistemas de SCM.

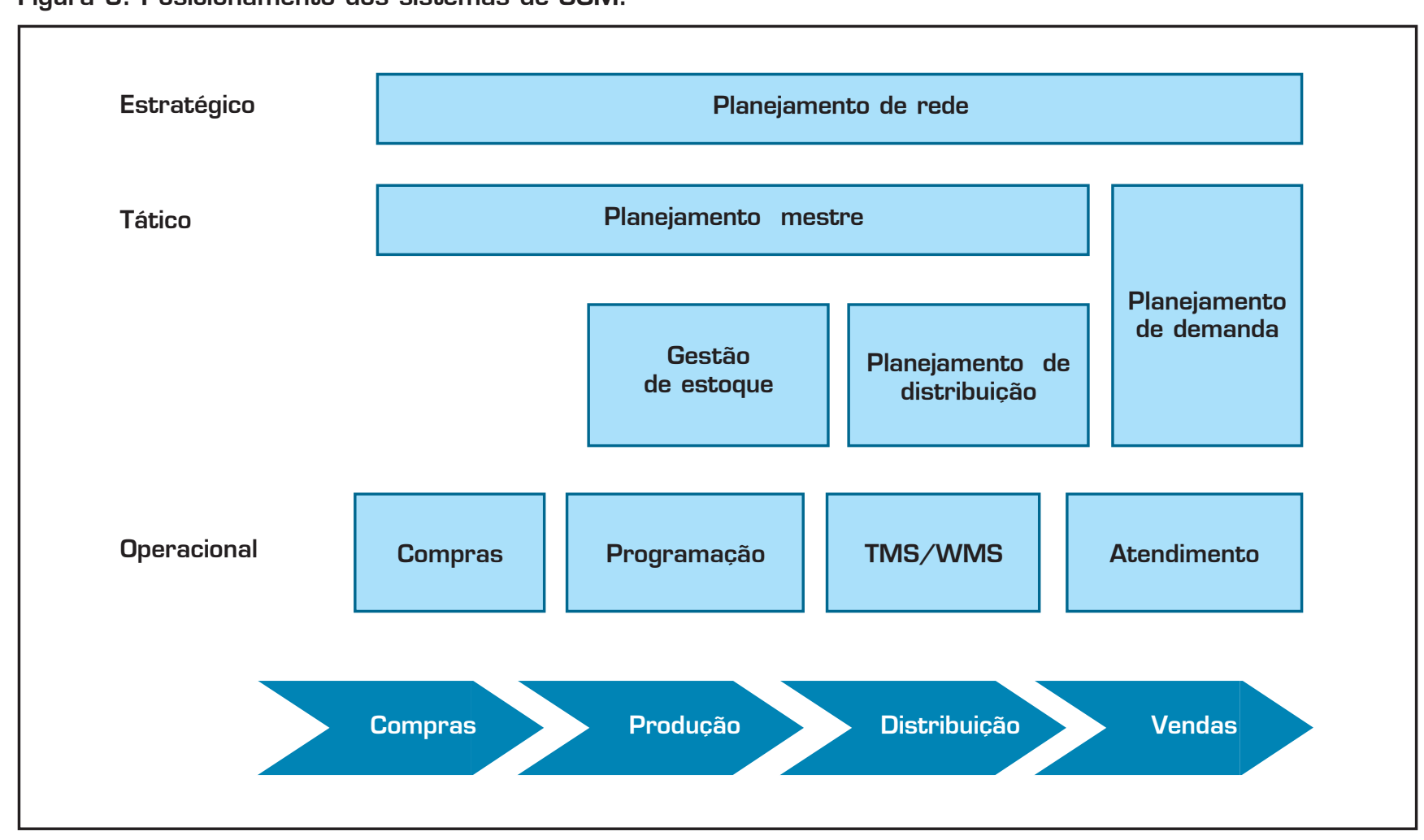

Fonte: Adaptado de Arozo (2003:124). 
O Sistema de Gerenciamento de Armazéns (WMS Warehouse Management System) é apenas uma parte dos Sistemas de Informação voltados à Armazenagem. Outros sistemas nesta área são o DRP (Distribution Requirements Planning ou Planejamento das Necessidades de Distribuição) e o TMS (Transportation Management Systems ou Sistemas de Gerenciamento de Transportes). Existem outros sistemas específicos e customizados. Todos visam garantir a qualidade e a velocidade das informações, racionalizando e otimizando a Logística de Armazenagem (BANZATO, 1998).

\section{WMS - WAREHOUSE MANAGEMENT SYSTEMS [SISTEMAS DE GERENCIAMENTO DE ARMAZÉNS]}

Para Arozo (2003), os sistemas de gerenciamento de depósitos e armazéns, ou WMS, são responsáveis pelo gerenciamento da operação do dia-a-dia de um armazém. Sua utilização está restrita a decisões totalmente operacionais, tais como: definição de rotas de coleta, definição de endereçamento dos produtos, entre outras.

Um WMS é um sistema de gestão integrada de armazéns, que operacionaliza de forma otimizada todas as atividades e seu fluxo de informações dentro do processo de armazenagem. Essas atividades incluem recebimento, inspeção, endereçamento, estocagem, separação, embalagem, carregamento, expedição, emissão de documentos, inventário, administração de contenedores entre outras, que, agindo de forma integrada, atendem às necessidades logísticas, evitando falhas e maximizando os recursos da empresa. gia de logística operacional direta de uma empresa, segundo Banzato (1998), entre elas:

- Planejamento e alocação de recursos;

- Portaria;

- Recebimento;

- Inspeção e controle de qualidade;

- Estocagem;

- Transferências;

- Expedição;

- Inventários;

- Controle de contenedores;

- Relatórios.

A descrição destas funções será discriminada no Quadro 2, juntamente com as sugestões de adaptação do WMS à logística reversa.

\section{METODOLOGIA DE UTILIZAC̣̃̃O DO WMS TRADICIONAL NO GERENCIAMENTO DA LOGÍSTICA REVERSA}

Inicialmente, buscou-se descobrir quais as dificuldades encontradas para as empresas gerenciarem seus resíduos. Esta identificação foi feita através de pesquisa exploratória in loco, com caráter qualitativo e natureza interpretativa. Através desta pesquisa, identificaram-se as necessidades em termos de Sistemas de Informações para o gerenciamento da Logística Reversa. As observações decorrentes permitiram a elaboração da proposta de adaptação do WMS tradicional para o gerenciamento da logística reversa em armazéns.

A maioria das empresas não tem definido em seus processos claramente a logística reversa, pois representa um percentual muito pequeno em relação aos valores movimentados pela logística direta. É por isso que não existem no mercado sistemas de informação específicos para seu controle. Isso representa uma deficiência para a empresa, pois se não houver sistemas de informação que operacionalizem o gerenciamento de resíduos, estes muitas vezes ficam na empresa ocupando um espaço inadequado, podendo gerar penalidades legais

Um sistema de WMS busca agilizar o fluxo de informações dentro de uma instalação de armazenagem, melhorando sua operacionalidade e promovendo a otimização do processo. Isto é feito pelo gerenciamento eficiente de informação e recursos, permitindo à empresa tirar o máximo proveito dessa atividade. O WMS deve se integrar aos sistemas de gestão de informações corporativos (ERP), e desta maneira contribuir para a integração da sistematização e automação dos processos na empresa.

O WMS possui diversas funções para apoiar a estraté- e obstruir o setor produtivo da empresa.

Em virtude da identificação desta deficiência em sistemas de informação de logística reversa e ao se analisar os softwares de Supply Chain Management existentes, constatou-se que é possível a customização de um WMS tradicional para o gerenciamento dos materiais ou resíduos de pós-consumo e pós-venda. Para tanto, foram analisados alguns aspectos considerados importantes para a proposta de adaptação do sistema. Estes aspectos, relativos a cada função do WMS, são descritos a seguir no Quadro 1. 
Quadro 1: Aspectos analisados para a proposta de adaptação.

\begin{tabular}{|c|c|}
\hline FUNÇÕES DO WMS & ASPECTOS ANALISADOS PARA A PROPOSTA DE ADAPTAÇÃO \\
\hline $\begin{array}{l}\text { Planejamento e } \\
\text { alocação de } \\
\text { recursos }\end{array}$ & $\begin{array}{l}\text { O planejamento dos recursos necessários para movimentação de materiais ou resíduos de } \\
\text { pós-consumo e pós-venda deve ser realizado como ocorre com as mercadorias usuais. Desta } \\
\text { forma cada material ou componente pode ser encaminhado ao destino apropriado } \\
\text { (retroprocessadores, transferência entre armazéns, devolução ao fornecedor, descarte final). }\end{array}$ \\
\hline Portaria & $\begin{array}{l}\text { Os veículos das empresas retroprocessadoras (responsáveis pelo encaminhamento dos } \\
\text { materiais de pós-consumo e pós-venda para revenda, recondicionamento, retorno ao } \\
\text { fornecedor, reciclagem ou descarte final) devem ser direcionados aos locais de despacho e } \\
\text { recebimento destes materiais, visando a otimização do fluxo. }\end{array}$ \\
\hline Recebimento & $\begin{array}{l}\text { Os materiais ou resíduos de pós-venda devem ser recebidos, identificados, ter os motivos } \\
\text { de retorno, procedência e quantidades confirmados, possibilitando sua estocagem em } \\
\text { quarentena até a inspeção e controle de qualidade. }\end{array}$ \\
\hline $\begin{array}{l}\text { Inspeção e controle } \\
\text { de qualidade }\end{array}$ & $\begin{array}{l}\text { Alguns materiais ou resíduos de pós-consumo (embalagens, paletes, berços, etc.) podem } \\
\text { ser reutilizados na atividade de armazenagem e os materiais ou resíduos de pós-venda } \\
\text { (mercadorias devolvidas por defeitos, avarias, etc.) podem ser reciclados, recondicionados, } \\
\text { retornados ao fornecedor ou revendidos. Para tanto devem ser inspecionados e avaliados para } \\
\text { verificação de suas condições e posterior destinação aos locais de estocagem provisória. }\end{array}$ \\
\hline Estocagem & $\begin{array}{l}\text { Os materiais ou resíduos de pós-consumo e pós-venda, embora constituam menor volume se } \\
\text { comparados às mercadorias usuais, devem ser estocados de forma organizada, possibilitando } \\
\text { a obtenção de informações sobre seu volume, realização de inventários e localização, além de } \\
\text { necessitarem de recursos e equipamentos para serem movimentados adequadamente. }\end{array}$ \\
\hline Transferências & $\begin{array}{l}\text { Através de dados obtidos na estocagem e inventário de mercadorias, existe a possibilidade } \\
\text { de verificação de excesso de alguns itens, bem como de avarias, expiração de prazo ou } \\
\text { defeitos nos itens estocados. Estes itens devem ser transferidos para outros armazéns que } \\
\text { necessitem de tais itens ou para retroprocessadores, revendas ou retorno ao fornecedor. } 0 \\
\text { fluxo de transferência entre armazéns ou demais empresas envolvidas deve ser gerenciado. }\end{array}$ \\
\hline Expedição & $\begin{array}{l}\text { Os materiais ou resíduos de pós-consumo e pós-venda precisam ser expedidos para os } \\
\text { locais destinados a agregar-lhes valor ou encarregados de realizar seu descarte: } \\
\text { retroprocessadores, fornecedores, revendas ou descarte final seguro. Esta expedição deve } \\
\text { ser devidamente documentada, roteirizada e organizada pelo armazém. }\end{array}$ \\
\hline Inventários & $\begin{array}{l}\text { Como ocorre com as mercadorias usuais da empresa, os materiais ou resíduos de pós- } \\
\text { consumo e pós-venda precisam ter seu volume e especificações conhecidos, bem como por } \\
\text { vezes necessitam de acertos de inventário e auditorias internas sem bloquear sua } \\
\text { movimentação. Estes materiais também necessitam de informações claras sobre suas } \\
\text { quantidades e não devem ser simplesmente "ocultados" pela empresa, pois constituem } \\
\text { retorno econômico considerável. }\end{array}$ \\
\hline $\begin{array}{l}\text { Controle de } \\
\text { contenedores }\end{array}$ & $\begin{array}{l}\text { Existem contenedores (paletes, racks, berços, cestos aramados, caixas plásticas, fitas de } \\
\text { arquear aço e plástico, papelão, entre outros) que são utilizados diversas vezes no } \\
\text { processo logístico direto. Estes materiais, quando no final de sua vida útil, não podem ser } \\
\text { simplesmente descartados, pois, algumas vezes, podem ser reciclados, revendidos, } \\
\text { recondicionados, de forma a estender sua vida útil e possibilitar economia para a empresa. } \\
\text { Para isso é necessário seu controle, como ocorre com os materiais novos. }\end{array}$ \\
\hline Relatórios & $\begin{array}{l}\text { Assim como ocorre com todos os processos realizados na logística direta, os materiais ou } \\
\text { resíduos movimentados pela logística reversa, constituem fonte de informações para os } \\
\text { administradores da empresa, para que se necessário sejam colocadas em prática ações } \\
\text { que visem otimizar este processo e reduzir custos. Para isso, são necessários relatórios } \\
\text { com todas as informações úteis para os usuários. }\end{array}$ \\
\hline
\end{tabular}


Com base nos aspectos analisados no Quadro 1, chegou-se até as sugestões de adaptação do WMS tradicional utilizado na logística direta, para utilização no gerenciamento da logística reversa. São apresentadas, no Quadro 2, estas funções e suas respectivas sugestões através de um comparativo. Apenas as funções do WMS consideradas correlacionadas com o gerenciamento da logística reversa estão destacadas no Quadro 2.
Baseados neste quadro, os passos sugeridos para a adaptação do WMS tradicional para o gerenciamento da logística reversa são:

1) As atividades de Planejamento e Alocação de Mão de Obra, Portaria e Recebimento atendem a necessidade do manuseio dos resíduos de pós-venda e pós-consumo que chegam ao armazém e necessitam ser acondicionados separadamente das mercadorias usuais;

Quadro 2: Adaptação do WMS tradicional para o gerenciamento da logística reversa.

\begin{tabular}{|c|c|c|}
\hline FUNÇÕES DO WMS & LOGÍSTIGA DIRETA & SUGESTÕES PARA LOGÍSTICA REVERSA \\
\hline $\begin{array}{l}\text { Planejamento e } \\
\text { alocação de } \\
\text { recursos }\end{array}$ & $\begin{array}{l}\text { Planeja automaticamente a alocação de mão- } \\
\text { de-obra diária, além do método de } \\
\text { movimentação de material e o equipamento } \\
\text { a ser utilizado por cada operador. }\end{array}$ & $\begin{array}{l}\text { Planejar automaticamente a alocação de } \\
\text { mão-de-obra e recursos para os operadores } \\
\text { movimentarem o material pós-consumo } \\
\text { (embalagens e outros) e pós-venda } \\
\text { (produtos devolvidos] por falhas e/ou avarias } \\
\text { ou problemas de validade. }\end{array}$ \\
\hline Portaria & $\begin{array}{l}\text { Controla todos os veículos envolvidos nas } \\
\text { operações de recebimento, gerenciando a fila } \\
\text { de espera e designação de docas, além de } \\
\text { controlar dados do fornecedor, ordem de } \\
\text { chegada, prioridade de descarga, etc. }\end{array}$ & $\begin{array}{l}\text { Controlar os veículos envolvidos nas } \\
\text { operações de recebimento e despacho de } \\
\text { material pós-consumo e pós-venda; } \\
\text { controlar dados de empresas } \\
\text { retroprocessadoras. }\end{array}$ \\
\hline Recebimento & $\begin{array}{l}\text { Identifica e seleciona o recebimento a ser } \\
\text { processado, indica os itens e quantidades a } \\
\text { serem recebidos, imprime e identifica o } \\
\text { produto, confirma o recebimento da } \\
\text { quantidade de cada produto e libera os itens } \\
\text { para a estocagem. }\end{array}$ & $\begin{array}{l}\text { Identificar e selecionar o recebimento de } \\
\text { material pós-venda (devolvido pelos } \\
\text { clientes), imprimindo e identificando o } \\
\text { produto, confirmando o recebimento e os } \\
\text { motivos de retorno, sua quantidade e os } \\
\text { liberando para estocagem provisória. }\end{array}$ \\
\hline $\begin{array}{l}\text { Inspeção e controle } \\
\text { de qualidade }\end{array}$ & $\begin{array}{l}\text { Notifica o operador de inspeção das } \\
\text { necessidades dos materiais recebidos, } \\
\text { permitindo a entrega imediata de produtos à } \\
\text { inspeção ou à notificação imediata para que } \\
\text { um inspetor venha à recepção; confirma e } \\
\text { libera a inspeção quando os produtos ficam } \\
\text { estocados em quarentena, evitando a } \\
\text { separação física do material. }\end{array}$ & $\begin{array}{l}\text { Identificar os produtos com defeitos, } \\
\text { problemas de validade, avarias em geral, } \\
\text { nas mercadorias recebidas; notificar } \\
\text { imediatamente as irregularidades e as } \\
\text { encaminhar para o estoque provisório } \\
\text { (quarentena) para posterior devolução à } \\
\text { fábrica ou envio a retroprocessadoras. }\end{array}$ \\
\hline Estocagem & $\begin{array}{l}\text { Analisa o melhor método de estocagem, } \\
\text { considerando local, tipo de equipamento, } \\
\text { momento oportuno para estocar; possibilita o } \\
\text { conhecimento do que está estocado; apóia o } \\
\text { recebimento do material que entra; a } \\
\text { consolidação de números de mesmo item; } \\
\text { inventário rotativo e zoneamento de áreas de } \\
\text { produtos. }\end{array}$ & $\begin{array}{l}\text { Analisar o melhor método de estocagem } \\
\text { temporária, considerando local, tipo de } \\
\text { equipamento; possibilitar o conhecimento } \\
\text { do volume estocado, dando apoio ao } \\
\text { recebimento; consolidar números de } \\
\text { mesmo item; fazer inventário rotativo e } \\
\text { zoneamento de áreas de produtos pós- } \\
\text { consumo e pós-venda. }\end{array}$ \\
\hline Transferências & $\begin{array}{l}\text { Gerencia os fluxos de transferência de itens } \\
\text { entre áreas, ou de um depósito para outro, } \\
\text { seja próprio ou terceirizado. }\end{array}$ & $\begin{array}{l}\text { Gerencia os fluxos de transferência entre } \\
\text { depósitos, fornecedor, retroprocessadores, } \\
\text { devido a problemas de devolução por garantia } \\
\text { ou validade, excesso de estoque ou materiais } \\
\text { no fim de sua vida útil (embalagens] para } \\
\text { serem reciclados ou revendidos. }\end{array}$ \\
\hline
\end{tabular}

(continua) 
(continuação do Quado 2)

\begin{tabular}{|c|c|c|}
\hline FUNÇÕES DO WMS & LOGÍSTICA DIRETA & SUGESTÕES PARA LOGÍSTICA REVERSA \\
\hline Expedição & $\begin{array}{l}\text { Inclui a roteirização dos produtos separados } \\
\text { para as devidas áreas de separação de cargas } \\
\text { na expedição; a geração automática dos } \\
\text { conhecimentos de embarque e atualização } \\
\text { automática de arquivos de pedidos abertos de } \\
\text { clientes. }\end{array}$ & $\begin{array}{l}\text { Incluir a roteirização dos produtos pós- } \\
\text { consumo e pós-venda para as devidas áreas } \\
\text { de separação de cargas de expedição, } \\
\text { gerando automaticamente os } \\
\text { conhecimentos de embarque para o } \\
\text { posterior envio aos retroprocessadores. }\end{array}$ \\
\hline Inventários & $\begin{array}{l}\text { Permite realizar os inventários físicos de } \\
\text { forma rápida e precisa, executando-os por } \\
\text { tipo de produtos ou localizações físicas; } \\
\text { também podem ser feitas auditorias internas } \\
\text { sem bloqueio de movimentação e de acordo } \\
\text { com os critérios da empresa, além de acertos } \\
\text { de inventários, tais como: quebra, mudança } \\
\text { de status de produtos, etc. }\end{array}$ & $\begin{array}{l}\text { Permitir a realização dos inventários físicos } \\
\text { de forma rápida e precisa dos produtos } \\
\text { pós-consumo e pós-venda, executando-os } \\
\text { por tipos de produtos ou por localização, } \\
\text { fazendo auditorias e acertos de inventários } \\
\text { mudando o status dos produtos para } \\
\text { produtos a serem encaminhados a } \\
\text { retroprocessadores ou destinação final nas } \\
\text { indústrias. }\end{array}$ \\
\hline $\begin{array}{l}\text { Controle de } \\
\text { contenedores }\end{array}$ & $\begin{array}{l}\text { Controla os contenedores como paletes, } \\
\text { racks, berços, cestos aramados, caixas } \\
\text { plásticas, fitas de arquear aço e plástico, } \\
\text { papelão, etc. }\end{array}$ & $\begin{array}{l}\text { Controlar os contenedores novos e também } \\
\text { os que estiverem no final de sua vida útil, } \\
\text { encaminhando-os para reciclagem ou } \\
\text { reutilização. }\end{array}$ \\
\hline Relatórios & $\begin{array}{l}\text { Fornece relatórios de desempenho e } \\
\text { informações operacionais que subsidiam o } \\
\text { processo de gerenciamento do armazém. }\end{array}$ & $\begin{array}{l}\text { Fornecer relatórios do montante de } \\
\text { materiais que são devolvidos, seus } \\
\text { respectivos motivos e demais informações } \\
\text { operacionais que subsidiam o } \\
\text { gerenciamento reverso do armazém. }\end{array}$ \\
\hline
\end{tabular}

Fonte: Adaptado de Banzato (1998).

2) Para operacionalizar a logística reversa de pós-venda: as atividades de Controle de Estocagem e Inventário verificam os itens que tiverem seu prazo de validade expirado ou eventuais problemas de qualidade. A atividade de Inspeção e Controle de Qualidade verifica no momento do recebimento de mercadorias, de fornecedores ou de outros armazéns, se os produtos estão dentro do prazo de validade e das condições de qualidade, caso contrário os encaminham para o estoque provisório. A atividade de Expedição encaminha esses itens de volta para os fornecedores, retroprocessadores ou em último caso à disposição final segura. No caso de medicamentos, especificamente, os fabricantes ou distribuidores têm a obrigação de trocá-los por produtos válidos;

3) Quando há excesso de estoque no armazém, essa situação deve ser também resolvida por meio de transferência desse excesso para outros armazéns ou devolução aos fornecedores. Para isso as atividades de Transferência e Expedição são utilizadas;

4) Para gerenciar os resíduos de pós-consumo, que são embalagens, fitas de arquear aço e plástico, papelão, paletes e outros, primeiramente devem ser separados, estocados e controlados, para isso são utilizadas as atividades de Estocagem e Controle de Contenedores. Posteriormente, esses resíduos devem ser enviados a centros de reciclagem ou retroprocessadores para que possam retornar ao processo produtivo. Para isso é utilizada a atividade de Expedição;

5) A atividade de Relatórios fornece informações sobre o montante das mercadorias devolvidas e seus respectivos motivos. Através dela é possível verificar eventuais erros internos que possam estar ocorrendo e providenciar sua regularização, além de ser importante fonte de informação para os sistemas corporativos;

6) Devem ser incluídos no Banco de Dados do WMS dados sobre empresas que realizem o recolhimento desses bens descartados, os retroprocessadores, que serão os responsáveis pelas destinações cabíveis.

Para que estas sugestões de adaptação sejam compreendidas e para ilustrar de melhor forma o sistema para gerenciamento da logística reversa, foram elaborados um diagrama de caso de uso, apresentado na Figura 4; um diagrama de classes das funções de recebimento e despa- 
cho na Figura 5 e outro diagrama de classes das funções relacionadas com controle de estoque e expedição, na Figura 6.

O diagrama apresentado na Figura 4 demonstra as funções do WMS tradicional, que são as mesmas utilizadas na sugestão de adaptação para o gerenciamento da logística reversa, onde as funções de estocagem, transferências, inventários, controles de contenedores e expedição são as diretamente relacionadas com a entrada e baixa das mercadorias no armazém. Todas possuem ligações entre si, não ocorrendo necessariamente na ordem apresentada. Após todos estes processos é possível a emissão de relatórios que forneçam as informações da movimentação das mercadorias aos usuários do sistema.

De acordo com Furlan (1998), na modelagem de casos de uso, não é importante compreender como o sistema implementa suas funções. Essa modelagem é utilizada para capturar as necessidades do sistema e também para desenvolver novas versões. Já no diagrama de classes, são listadas as funcionalidades que o sistema deverá abranger. Esse diagrama é mais específico, pois mostra as operações que provavelmente serão implementadas.

$\mathrm{Na}$ Figura 5, são apresentadas as atividades do WMS tradicional e os atributos sugeridos para o gerenciamento da logística reversa em armazéns através de um diagrama de classe, no que se refere às atividades de recebimento e despacho de mercadorias.

Conforme demonstrado na Figura 5, as funções do sistema devem ter a interação de um usuário que necessita de código, nome e senha. O sistema permite sua inclusão, alteração e exclusão. A função de Planejamento e Alocação de Recursos é responsável por planejar e alocar mão-de-obra e recursos materiais necessários à movimentação dos materiais ou resíduos de pós-consumo e pós-venda no armazém. A função de Inspeção e Controle de Qualidade identifica os produtos com defeito, identifica irregularidades, encaminha para estocagem provisória, libera para devolução ao fornecedor ou envio aos retroprocessadores. A função de Portaria controla e encaminha os veículos de recebimento e despacho dos

Figura 4: Diagrama de caso de uso - WMS.

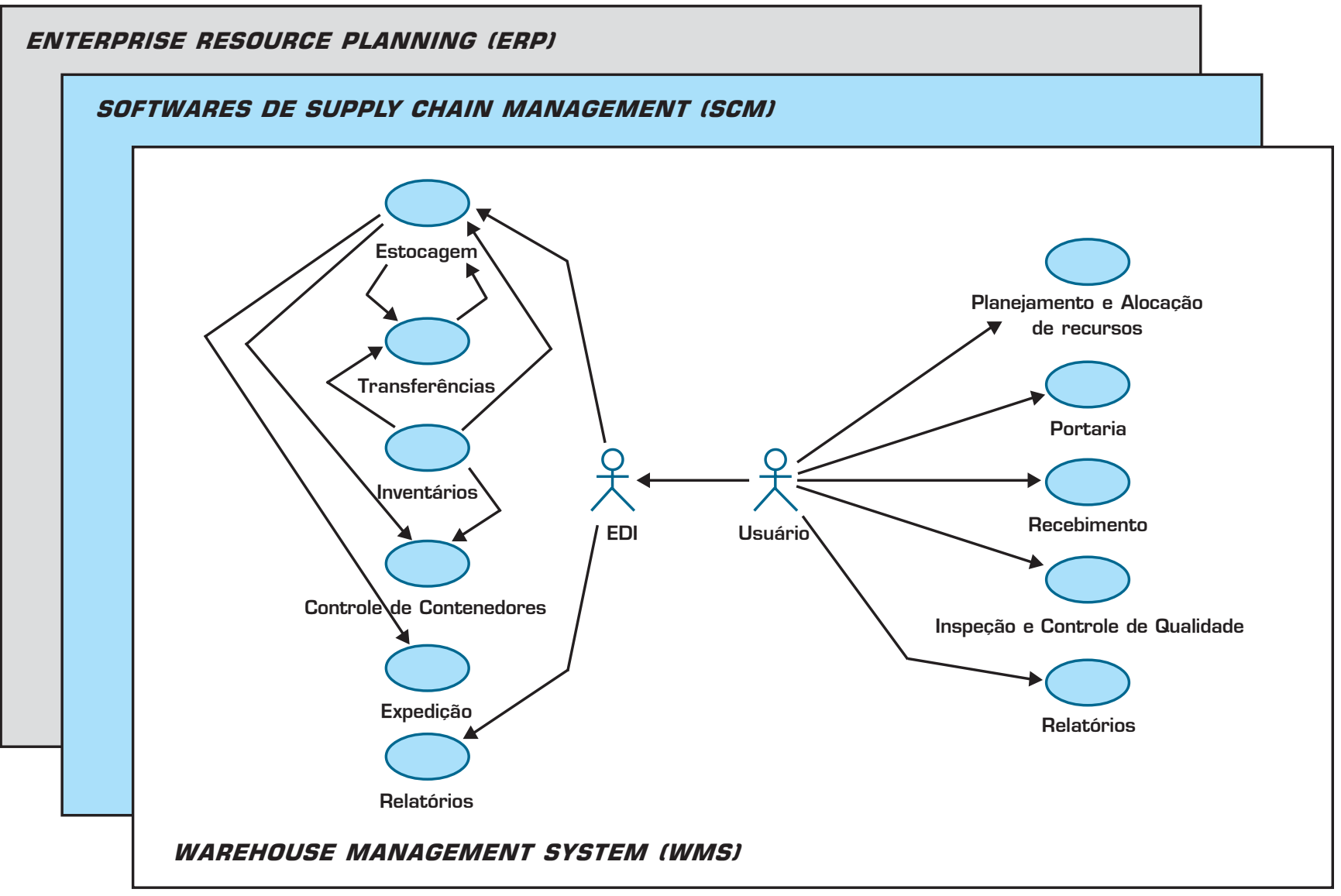


materiais ou resíduos de pós-venda e pós-consumo e controla os dados das empresas retroprocessadoras. A função de Recebimento é responsável pela identificação do material recebido, sua seleção, impressão, confirmação, identificação de motivos de retorno e volume retornado e libera os mesmos para estocagem provisória no armazém. E por fim a função de Relatórios apresenta as informações relevantes ocorridas em todo o processo.

Apresenta-se a seguir, na Figura 6, outro diagrama de classes que abrange as atividades relacionadas ao controle de estoques dos materiais ou resíduos de pós-consumo e pós-venda, bem como de sua transferência e expedição para outros armazéns, retorno aos fornecedores ou envio às empresas retroprocessadoras.

Figura 5: Diagrama de classe de atividades de recebimento e despacho de mercadorias.

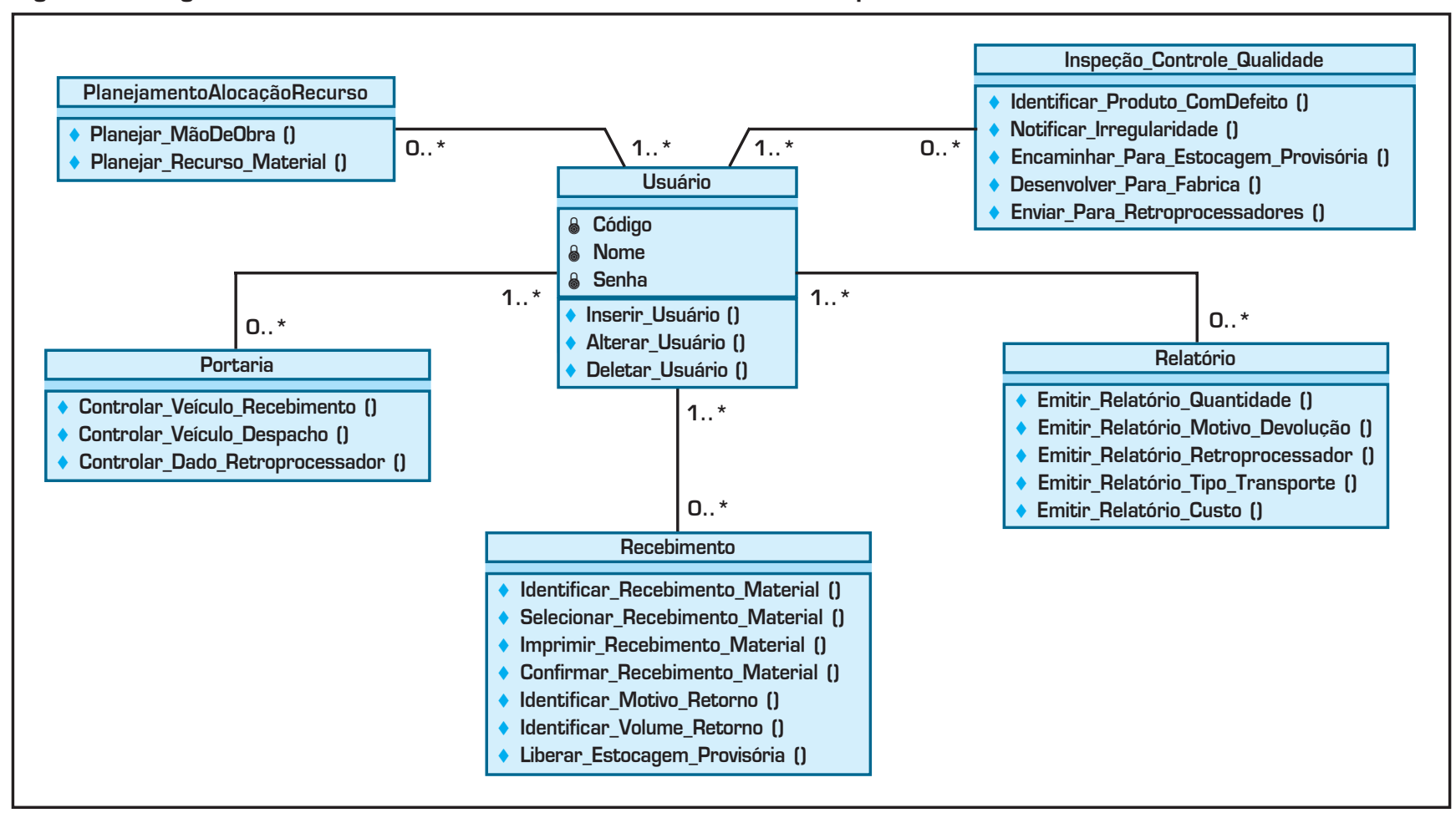

Figura 6: Diagrama de classe de atividades de controle de estoques.

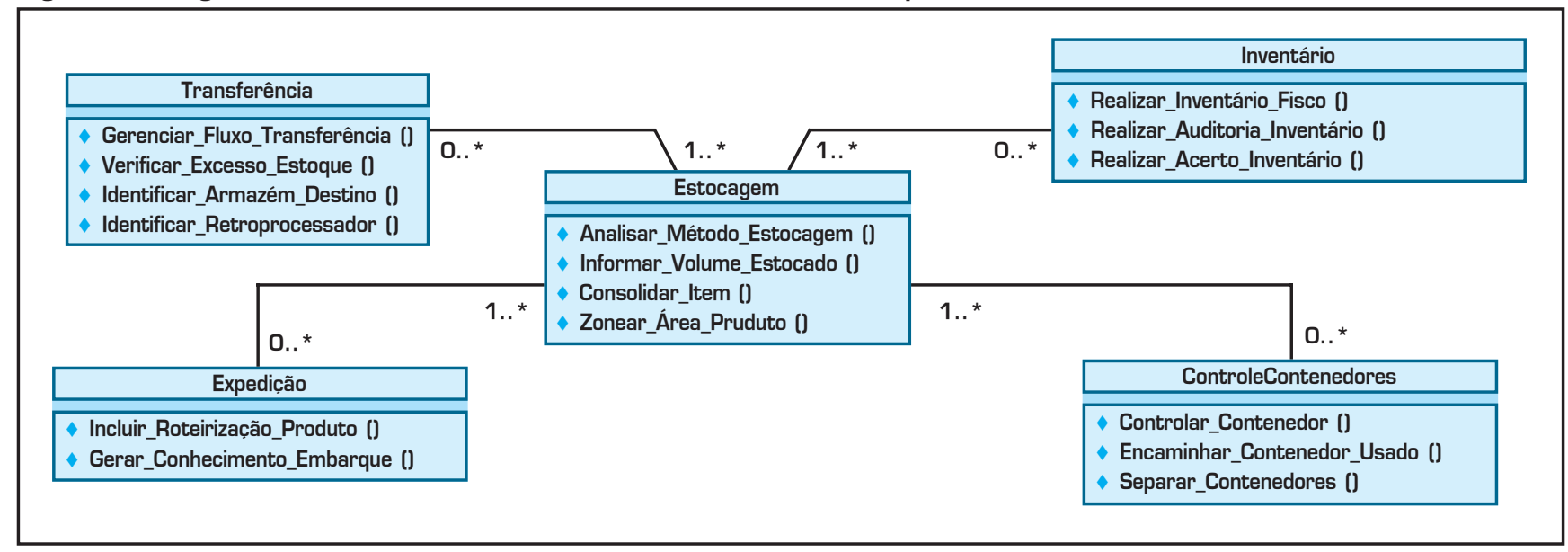


Na Figura 6 são apresentadas as atividades relacionadas aos estoques que possuem constante troca de informações. A função de Estocagem na proposta de adaptação do sistema tradicional fica responsável por analisar o melhor método de estocagem dos materiais ou resíduos de pós-consumo e pós-venda, informar o volume estocado, consolidar os itens em estoque e efetuar zoneamento de áreas de produtos. A função de Inventário realiza os inventários físicos dos materiais estocados, realiza auditoria e acertos de inventário quando necessário, além de detectar se existem produtos que devem ser transferidos para outros armazéns, retroprocessadores ou devolvidos aos fornecedores. A função de Transferência é acionada quando a função de Inventário detecta excesso de alguns itens e torna-se responsável pelo gerenciamento do fluxo de transferência dos mesmos, selecionando retroprocessadores ou armazéns para o envio. A função de Controle de Contenedores (racks, berços, paletes, papelão, etc.), efetua o controle destes materiais, separa os contenedores usados e os encaminha para recondicionamento, reutilização, reciclagem ou disposição final, além de providenciar os contenedores adequados para a movimentação das mercadorias. A função de expedição inclui roteirização dos materiais ou resíduos de pós-consumo e pós-venda a serem despachados para retroprocessadores, retorno aos fornecedores ou outros armazéns, bem como gera os conhecimentos de embarque necessários.

Os diagramas de casos de uso e os diagramas de classe visam modelar um sistema. Porém, suas representações mostram pontos de vista diferentes. Como citado anteriormente, o diagrama de caso de uso mostra, de uma forma genérica, o esboço do sistema, através de uma prévia identificação das principais necessidades dos usuários. Enquanto no diagrama de classes são apresentadas, de forma específica, as funcionalidades através de métodos que serão implementados, além dos atributos que serão necessários para a alimentação dos dados do sistema. Dessa maneira, os dois diagramas são complementares no sentido de proporcionar uma visão da sugestão de adaptação a que o artigo se propõe.

Ainda ressalta-se que estes diagramas têm o objetivo de demonstrar uma adaptação genérica do WMS tradicional, o que pode e deve ser readequado diante das necessidades de cada empresa.

\section{CONSIDERACÕES FINAIS}

A inexistência de sistemas para gerenciamento da logística reversa no mercado pode ser contornada através da utilização de sistemas já existentes, como por exemplo um WMS tradicional.

Para identificar os requisitos necessários a esta ativi- dade, efetuou-se uma pesquisa exploratória in loco, a fim de identificar quais as necessidades das empresas no que se refere a Sistemas de Informações para o gerenciamento da Logística Reversa.

A pesquisa evidenciou que as necessidades são as mesmas encontradas na literatura, que mostra que a maioria das empresas não tem definida em seus processos a logística reversa, bem como não possuei sistemas de informações que a gerencie. Tais sistemas facilitam o fluxo de produtos e informações e otimizam os recursos da empresa.

Efetuou-se um quadro comparativo de funções entre os sistemas WMS tradicionais e o que seria necessário para o gerenciamento da logística reversa.

A partir da pesquisa realizada e do quadro comparativo, foi proposta uma metodologia de utilização do WMS tradicional, composta por dez atividades. Para ilustrar de melhor forma, foram elaborados um diagrama de caso de uso e dois diagramas de classe que apresentam as sugestões de adaptação do sistema para o gerenciamento da logística reversa. Salienta-se que estas atividades são as correlacionadas com a logística reversa e que o sistema tradicional apresenta ainda outras atividades, não salutares ao caso em questão.

Os resultados demonstram que a aplicação da metodologia é viável e permite a utilização adequada dos sistemas WMS tradicionais para gerenciamento da logística reversa. Desta maneira, a carência de sistemas na área é suprida de maneira eficiente.

As vantagens desta solução, para uma empresa que já possua WMS tradicional, são:

1) utilizar um sistema já implantado na empresa;

2) aproveitar o treinamento das pessoas que já estão envolvidas com tal sistema;

3) reduzir os custos e prazos de implantação do sistema;

4) reduzir os custos e o tempo de operacionalização do gerenciamento da logística reversa em armazéns;

5) desobstruir espaços físicos dentro do armazéns, ocupados pelos resíduos.

Dessa forma, nota-se que a adaptação do WMS tradicional para o gerenciamento da logística reversa é possível e resolve a necessidade imediata das empresas em gerenciar seus resíduos de forma mais organizada, racionalizando tempo e recursos até o momento em que sejam desenvolvidos sistemas específicos para tal função. Por carência de tais sistemas, as empresas podem incorrer em problemas ambientais, logísticos e econômicos, pois a operacionalização da logística reversa de forma manual envolve maior número de pessoas e maior tempo, recursos importantes que poderiam estar voltados ao verdadeiro foco da empresa. 


\section{Artigo recebido em 08/07/2005 Aprovado para publicação em 29/11/2005}

\section{- Referências Bibliográficas}

ARBACHE, F. S.; SANTOS, A. G.; MONTENEGRO, C. \& SALLES, W. F. Gestão de logística, distribuição e trade marketing. Editora FGV: Rio de Janeiro, 2004 .

BALLOU, R. H. Gerenciamento da cadeia de suprimentos: Planejamento, organização e logística empresarial. Porto Alegre: Bookman, 2001.

BANZATO, E. WMS - Warehouse management system: Sistema de gerenciamento de armazéns. São Paulo: IMAN, 1998.
BOWERSOX, D. J. \& CLOSS, D. J. Logística empresarial. São Paulo: Atlas, 2001.

CHOPRA, S. \& MEINDL, P. Gerenciamento da cadeia de suprimentos: Estratégia, planejamento e operação. São Paulo: Prentice Hall, 2003.

AROZO, R. Softwares de supply chain management: Definições, principais funcionalidades e implantacão por empresas brasileiras. In: FIGUEIREDO, K. F. FLEURY, P. F \& WANKE, P. Logística e gerenciamento da cadeia de suprimentos: Plane- jamento do fluxo de produtos e dos recursos. São Paulo: Atlas, 2003.

FURLAN, J. D. Modelagem de objetos através da UML - The Unified Modeling Language: análise e desenho orientados a objeto. São Paulo: Makron Books, 1998.

GOMES, C. F. S. \& RIBEIRO, P. C. C. Gestão da cadeia de suprimentos integrada à tecnologia da informação. São Paulo: Pioneira Thomson Learning, 2004.

LEITE, P. R. Logística Reversa. São Paulo: Prentice Hall, 2003.
POZO, H. Administração de recursos materiais e patrimoniais. São Paulo: Atlas, 2002.

ROGERS, D. S. \& TIBBEN-LEMBKE, R. S. Going backwards: reverse logistics trends and practices. Reno: Universidade de Nevada, 1999.

VERISSIMO, N. \& MUSETTI, M. A. A tecnologia de informação na gestão de armazenagem. In: Encontro Nacional de Engenharia de Produção, 23, 2003, Ouro Preto, Anais... Ouro Preto: ENEGEP, 2003. 1 CD-ROM.

\section{- Agradecimentos}

Os autores agradecem à Capes pelo apoio financeiro que possibilitou a elaboração do presente trabalho.

\section{- Sobre os autores}

\section{Patrícia Guarnieri}

Especialista em Gestão Empresarial (CEFET - PR), mestranda do curso de pós-graduação stricto sensu em Engenharia da Produção (CEFET - PR), bolsista da Capes.

Endereço: Rua Goiás, 400, Ap. 14 - Ed Harmonia - Bairro Órfãs - CEP 84010-650 - Ponta Grossa - PR.

Telefones: (42) 9104-1500, (42) 3222-7763 E-mail: patriciaguarnieri@ibest.com.br

\section{Daniele Chrusciack}

Graduada em Informática (UNIOESTE - PR), especialista em Docência no Ensino Superior (UNIPAN - PR), professora do curso de Ciências da Computação na disciplina de Engenharia de Software na UNIPAN - PR.

Endereço: Rua Joaquim Távora, 1090 - Bairro Parque São Paulo - CEP 85803-750 - Cascavel - PR.

Telefones: (45) 9962-5642, (45) 3223-0080_E-mail: chrusca@terra.com.br

\section{Ivanir Luiz de Oliveira}

Doutor em Ciência e Engenharia de Materiais pela UFSCAR - SP, professor do programa de pós-graduação em Engenharia da Produção do CEFET - PR

Endereço: Rua Adjaniro Cardon , 56 - J. Carvalho - CEP 84015-580 - Ponta Grossa - PR

Telefones: (42) 3223-3251, (42) 3220-4805, (42) 3220-4810Ｅ-mail: ivanir@pg.cefetpr.br

\section{Kazuo Hatakeyama}

Doutor em Engenharia Mecânica, University of Wales - UK, pós-doutor em Administração do Ensino Superior, University of Manchester - UK, coordenador e professor do programa de pós-graduação em Engenharia da Produção do CEFET - PR.

Endereço: Av. Monteiro Lobato, s/n, km 4 - cx postal 20 - CEP 84016-210 - Ponta Grossa - PR.

Telefone: (42) 3220-4805_E-mail: khatakeyama@uol.com.br

\section{Luciano Scandelari}

Doutor em Instrumentação Industrial, Université Joseph Fourier - França, professor do programa de pós-graduação em Engenharia da Produção do CEFET - PR.

Endereço: Rua Cel. João mattos Guedes, 123 - CEP 82200-370 - Curitiba - PR.

Telefones: (41) 3229-5240, (41) 9228-0289Ｅ-mail: luciano@ cefetpr.br 